\title{
Sistemas públicos universais de saúde e participação popular: 0 papel do Judiciário
}

Universal public health systems and public participation: the role of the judiciary

\begin{abstract}
Sueli Gandolfi Dallari
Advogada. Coordenadora Científica do Núcleo de Pesquisas em Direito Sanitário da Universidade de São Paulo; Professora Titular da Faculdade de Saúde Pública da Universidade de São Paulo; Professeur Invitée da Faculté de Droit da Université de Paris Descartes - Paris, França; Professeur Invitée da Faculté de Droit da Université de Paris X - Nanterre, França; Professeur Invitée da Faculté de Droit da Université de Nantes, França; Tinker Professor da School of International and Public Affairs, da Columbia University, Estados Unidos da América. São Paulo, Brasil.
\end{abstract}

Resumo: Foi feita uma análise da situação atual do confronto entre a cobertura universal de assistência médica e sistemas públicos universais de saúde nos documentos internacionais. Verificou-se a necessidade de fortalecer a resposta dos Estados nos fóruns internacionais, tanto através da participação direta neles como pelo incremento da participação interna. Constatou-se que o Estado Democrático de Direito exige a participação do público na formulação e implementação de políticas públicas e que esta novidade constitucional do final do século XX requer, por sua vez, a atenção especial do Poder Judiciário no controle das políticas públicas. Isso porque a participação popular gera um novo tipo de ato normativo: não é legislativo nem administrativo, mas é essencialmente público.

Palavras-chave: sistema público universal de saúde; políticas públicas; Estado Democrático de Direito; Direito Sanitário.

Resumen: Se hizo una revisión de la situación actual de la confrontación entre la cobertura de atención médica universal y los sistemas universales de salud pública en los documentos internacionales. Se verificó la necesidad de fortalecer la respuesta de los Estados en los foros internacionales, tanto a través de la participación directa en ellos como por el aumento de la participación interna. Se encontró que el Estado de Derecho Democrático exige la participación del público en la formulación y ejecución de políticas públicas y que esta novedad constitucional de fines del siglo XX requiere, a su vez, la atención especial de la judicatura en el control de las políticas públicas. Esto se debe a que la participación popular genera un nuevo tipo de acto normativo: no es legislativo ni administrativo, pero es esencialmente público.

Palabras clave: sistemas públicos universales de salud; políticas públicas; Estado Democrático de Derecho; Derecho Sanitario

Abstract: A review of the current situation of the confrontation between universal health care coverage and universal public health systems in international documents was done. A need to strengthen the response of States in international fora both through direct participation in them as by increasing domestic participation was verified. It was found that the democratic rule of law requires public participation in the formulation and implementation of public policies and that this constitutional novelty of the late twentieth century requires, in turn, the special attention of the judiciary in 
controlling public policy. That's because the popular participation generates a new type of normative act: it is not legislative nor administrative, but it is essentially public.

Key words: universal public health system; public policy; Democratic Rule of Law; Health Law

No campo dos valores, vivemos um conflito já não mais abafado, mas amplamente iluminado, entre o discurso dos direitos humanos e aquele da ordem financeira, que enxerga a atenção à saúde como uma mercadoria, por exemplo.

E o pior é que o acesso ao aparato judiciário é outro bom exemplo desse confronto: ele configura o direito humano de acesso à justiça ou é apenas um produto social, podendo ser apreçado no mercado?

É importante notar que essa tensão não se limita às fronteiras brasileiras, sendo encontrada tanto nos demais Estados contemporâneos quanto nos foros internacionais. Veja-se, por exemplo, a defesa - que acontece agora tanto na Organização Mundial da Saúde quanto nos encontros de cúpula dos países emergentes (BRICS) e na própria Assembleia da Organização das Nações Unidas (ONU, 2011) - da simples extensão da cobertura por serviços de assistência médica que, no dizer de seus detratores, não será capaz de atender aos muitos outros programas de saúde pública, indispensáveis para assegurar "uma visão mais ampla, com um conjunto de objetivos com metas e indicadores de prevenção, tratamento, determinantes sociais, sistemas de saúde, mudanças climáticas e equidade, entre outras preocupações" (Horton, 2012).

Assim, os argumentos variam da necessidade de "estabelecer e estimular uma agenda sanitária global para o acesso universal a medicamentos e bens de saúde; sublinhando o importante papel dos medicamentos genéricos na realização do direito à saúde" (BRICS, 2014) até a afirmação de que os programas de ajuste, levando os governos a diminuir gastos públicos e ao desenvolvimento de um setor privado que visa o lucro, dentro de uma lógica de mercado, não produzirão "saúde".

Em maio de 2013, ministros de estado do Brasil, da França, da Indonésia, da Noruega, do Senegal, da África do Sul e da Tailândia assinaram um documento conjunto afirmando acreditarem que, entre as várias opções para os objetivos relacionados à saúde na Agenda das Nações Unidas para Além de 2015, a cobertura sanitária universal seja um bom indicador (Canfin et al., 2013). Dizem eles que ela é "crucial para o aumento da expectativa de vida, para erradicar a pobreza, para 
promover equidade e para alcançar o desenvolvimento sustentável. A cobertura sanitária universal também representa a oportunidade de melhorar o desempenho dos sistemas de saúde e os resultados da prestação de serviços".

Esses ministros, entretanto, julgaram conveniente esclarecer o que entendem por cobertura sanitária universal: "implica que todas as pessoas tenham acesso, sem discriminação, a conjuntos de serviços básicos de promoção, prevenção, curativos e de reabilitação da saúde, determinados nacionalmente, e aos medicamentos essenciais, seguros, acessíveis, efetivos e de qualidade".

Eles faziam eco ao documento de consenso aprovado na 67ạ Sessão Plenária da Assembleia Geral das Nações Unidas que encorajava os governos a planejar ou prosseguir a transição para o acesso universal a serviços de saúde acessíveis e de qualidade (ONU, 2012).

A argumentação apresentada pelo Japão foi bastante enfática ao afirmar que a cobertura sanitária universal é o caminho para resolver os desafios sanitários globais, especialmente porque é crucial para superar a lacuna entre ricos e pobres no acesso aos serviços de saúde, permitindo a mudança da abordagem orientada pela doença para outra centrada nas pessoas, mas, sobretudo, porque capacita os países a olhar para seus próprios desafios e implementar as políticas de saúde que atendam diversas necessidades com um orçamento limitado. O Primeiro Ministro daquele país, ao lembrar o sucesso japonês na melhora da equidade no sistema de saúde, na expansão da cobertura para os cidadãos e no controle do custo dos serviços, não esconde a estratégia que ele espera ver adotada: o seguro sanitário universal (Abe, 2013).

Em suma: ainda há muito que esclarecer para que possamos ter segurança de que todos estão de acordo com o documento relativo ao tema 7.4 da Agenda

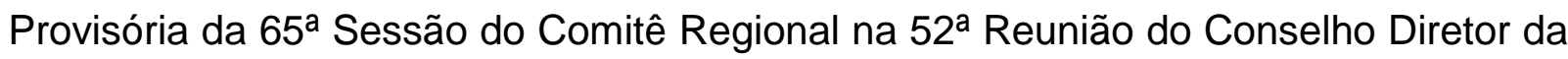
Organização Pan-Americana de Saúde, que se reuniu na semana de 30 de setembro a 4 de outubro de 2013: é necessário "priorizar o acesso universal à saúde, entendido como a garantia do direito à saúde, respondendo não apenas à cobertura dos serviços de saúde, mas também às intervenções nos determinantes sociais da saúde, como o objetivo prioritário a ser apresentado na Agenda de Desenvolvimento pós2015. Propõe-se, também, [...] impulsionar a cobertura universal que deve incluir o acesso a todas as intervenções importantes, e fortalecer os sistemas de saúde, como metas." (OPAS, 2013). 
Como construir uma resposta latina forte em defesa do sistema público universal de saúde?

Certamente o convencimento das altas esferas governamentais é indispensável para afirmar a posição dos Estados na elaboração das Metas para o Desenvolvimento para Depois de 2015. E quanto a isso, até agora, pode-se confiar que eles seguirão o que acabam de decidir na Organização Pan-Americana de Saúde.

Importa, contudo, aproveitar os espaços disponíveis para que cada pessoa possa fazer valer sua opção nesse debate. Para isso é importante considerar, também, as oportunidades abertas no The United Nations Non-Governmental Liaison Service (UN-NGLS), destinado a promover e desenvolver relações construtivas entre as Nações Unidas e as organizações da sociedade civil.

Com efeito, apesar de ter havido, desde sempre, um estímulo para que o Conselho Econômico e Social promovesse consultas com organizações não governamentais (Carta da ONU, art. 71), apenas nos anos 1990 a presença de ONG se consolida no sistema ONU, incluindo ONG, coalisões e alianças até mesmo nacionais. E a Declaração do Milênio (setembro de 2000) é um bom exemplo da importância reconhecida a essa participação política na governança global.

Mas não só: há muito a ser realizado na órbita dos Estados em termos de esforços de advocacia, tanto no campo estritamente político quanto naquele jurídico.

Construir um conceito de sistema público universal de saúde a partir de fóruns de discussão que permitam sua gênese democrática, como ensinou Habermas (1997), é indispensável. Tão essencial quanto essa construção, porém, é a realização do direito assim gerado. E para isso alguns cuidados devem ser tomados.

O Estado Democrático de Direito reconhece a democracia como tempero necessário à fórmula moderna do Estado. As pessoas devem assumir o controle das ações e das políticas públicas e o discurso da participação é tema de quase todas as campanhas eleitorais (Bevort, 2002). Quer-se efetivamente incorporar o povo nos mecanismos do controle das decisões (Silva, 1992).

Esse entusiasmo pela intervenção direta do povo na atividade de produção das leis e de políticas governamentais não pode, entretanto, embaçar a percepção de que ela é contemporânea à chamada globalização da economia capitalista, cujas características marcantes incluem a revitalização da crença no caráter autorregulador dos mecanismos de mercado; a crescente desregulamentação das atividades 
econômicas e a destituição dos direitos sociais; uma erosão da soberania e da capacidade decisória do Estado, seja pela crescente emergência de novos atores regionais e globais (blocos de integração econômica, conglomerados transnacionais), seja pela política de privatizações, no plano interno; uma diminuição da capacidade de resposta do Estado aos conflitos sociais contemporâneos, que vão assumindo uma dimensão claramente global (terrorismo, narcotráfico, lavagem de dinheiro, degradação ambiental, tráfico de pessoas e de órgãos), enquanto os Estados permanecem adstritos aos limites dos territórios nacionais (Minhoto e Martins, 2002).

Essa mudança estrutural do contexto traz, portanto, o desafio da legitimidade dos procedimentos para a legitimação do exercício do princípio democrático.

No campo da saúde, por exemplo, trata-se agora, de enfrentar o "mercado da doença", que privilegia os aspectos econômicos e financeiros das atividades inerentes à organização dos serviços e produtos de saúde. E isto porque, nesse ambiente voltado para cuidar da saúde como uma questão de acesso a serviços de assistência às pessoas doentes, no contexto da chamada "saúde global", ficou demonstrado que os programas de ajuste, levando os governos a diminuir gastos públicos e ao desenvolvimento de um setor privado que visa o lucro, dentro de uma lógica de mercado, não produziu saúde.

Por outro lado, deve-se evitar, também, a entronização da figura econômica do consumidor, que "nega a necessidade de serem tomadas decisões políticas, que são precisamente as decisões a respeito de interesses comuns ou de grupos, contrapostas à soma de opções, racionais ou não, de indivíduos que se norteiam por suas preferências particulares. A participação no mercado substitui a participação na política. O consumidor toma o lugar do cidadão" (Hobsbawn, 2001).

A resposta capaz de instituir um controle democrático sobre as diversas formas de participação popular no governo já adotadas por diversos países e cara aos estudiosos - que parecem não haver encontrado outras possibilidades para a democracia atual - implica certamente a análise das possibilidades de ação deixadas para o Judiciário para o controle jurisdicional da participação popular nas políticas públicas.

É preciso, contudo, que os juízes e demais profissionais do campo jurídico conheçam bem o Direito do Século XXI, que não se contenta com a simples existência de textos legais regulando a matéria, mas exige a verificação do efetivo controle popular na implementação da política pública. 
É, portanto, inadequado considerar o poder normativo do Estado como pertencendo exclusivamente aos poderes consagrados na teoria da separação de poderes do Estado. De fato, a construção de órgãos e mecanismos que asseguram a participação direta do povo na definição e o contínuo controle popular dos atos de implementação das políticas públicas permitem ao menos identificar outra esfera de poder normativo, que talvez possa ser denominada de eminentemente pública.

É preciso, portanto, que o julgador seja capaz de identificar não apenas os argumentos que têm como base atos legislativos em sentido próprio, mas também aqueles que se originam no poder normativo da Administração e, ainda, os que têm fundamento no poder normativo propriamente público, derivado da efetiva participação das pessoas na definição e na realização do direito à saúde.

Mais ainda, o Judiciário tem a tarefa de confrontar as políticas públicas com os padrões jurídicos aplicáveis ao caso concreto e, na hipótese de encontrar divergências, reenviar a questão aos poderes pertinentes para que ajustem sua atuação (Abramovich e Courts, 2004, p. 251).

Percebe-se, assim, que o jurista, cuidando de uma política pública, está obrigado a encontrar o ato normativo que formaliza a tradução do direito gerado da participação popular. O que implica afirmar, também, que o legislador/administrador deve formalizar tal tradução. Tendo-se sempre presente que a análise de políticas públicas exige um trabalho sequencial, deve-se inicialmente, determinando o quadro geral em que ela atua, identificar o conjunto de medidas concretas com objetivo e públicos certos.

Todas essas medidas devem ter uma tradução jurídica. Elas estarão contidas em decretos, portarias, resoluções, legislação orçamentária e financeira, contratos e convênios, licenças e autorizações etc.. O caráter essencialmente procedimental do trabalho com políticas públicas implica, portanto, a identificação de cada etapa e, para o jurista, de cada documento onde ela está contida. Trata-se, portanto, de assegurarse de que o documento que identifica cada etapa da política revele que ele foi construído com a efetiva participação de todos os interessados.

Concluindo, é fácil supor que a participação popular, até mesmo por implicar a contestação da tradicional representação política concebida na Modernidade, tende a ser fortemente contestada pela ideologia dominante. 
É igualmente fácil aceitar que a experiência de participação tem um caráter para dizer pouco - ambíguo, existindo elementos que caracterizam tanto seu sucesso quanto seu fracasso.

Por outro lado, é preciso reconhecer que a atual cultura jurídica não encontra meio mais apropriado para definir o que constitui um direito que o procedimento institucionalizado, combinando a participação direta do povo na administração pública ao regular exercício do poder administrativo pelos representantes eleitos.

Ora, se o Direito atual - configurado no ambiente de prevalência dos direitos humanos e do novo constitucionalismo, em sociedades complexas - exige procedimentos democráticos tanto para sua determinação quanto para sua realização, pode-se concluir que os juízes perdem a possibilidade de conceber sua "interpretação construtiva como um empreendimento comum, sustentado pela comunicação pública dos cidadãos" (Habermas, 1997, p. 474), quando não buscam de forma cooperativa a verdade.

Esse labor seria grandemente facilitado se tanto a legislação em sentido próprio quanto os atos administrativos começassem declarando como foram constituídos, nomeando pessoas e organizações e explicando os processos de participação popular empregados na feitura da norma. Isso permitiria que um juiz, que deva apreciar em eventual disputa o respeito ao mandamento constitucional que exige que o poder seja exercido pelo povo por meio de representantes eleitos e também diretamente, consiga apurar - com a desejável agilidade - a formalidade de cada etapa do procedimento destinado à realização do direito.

O julgador deve ser capaz de distinguir, assim, o exercício do poder normativo pela Administração daquele eminentemente Público, exercido diretamente pelo povo, ainda que formalizado em atos normativos da Administração.

E, sobretudo, ele deve ser capaz de reconhecer o conceito de sistema público universal de saúde gerado nos fóruns de discussão democrática.

\section{Referências}

ABE, Shinzo. Comment: Japan's strategy for global health diplomacy: why it matters. The Lancet, 382(9896):915-6, 14 sep. 2013. [ISSN n. fornecido]

ABRAMOVICH, Victor \& COURTS, Christian. Los derechos sociales como derechos exigibles. Madrid: Trotta, 2004. ISBN 84-8164-507-9

BEVORT, Antoine. Pour une democratie participative. Paris: Presses de Sciences Politics, 2002. ISBN 978-2724608847 
BRICS Health Ministers' Meeting: Beijing Declaration. Jul 2011. Nova Yorque: Council on Foreign Relations. 7 May 2014. [on line] Disponível em: http://www.cfr.org/globalhealth/brics-health-ministers-meeting----beijing-declaration/p25620

CANFIN, Pascal. et al.. Our common vision for the positioning and role of health to advance the UN development agenda beyond 2015. The Lancet; 381(9881):1885-6, 1 jun. 2013. doi: 10.1016/S0140-6736(13)60952-6. [ISSN n. fornecido]

HABERMAS, Jürgen. Droit et democratie: entre faits et normes. Paris: Gallimard, 1997. ISBN 2-07-073352-1

HOBSBAWM, Eric. A falência da democracia. Folha de S. Paulo, Caderno Mais!, 9 set. 2001. [on line] Disponível em: www1.folha.uol.com.br/fsp/mais/fs090920015.htm Acesso em 22 out. 2014)

HORTON, Richard. Offline: The advantages of Universal Health. The Lancet, 30(9854):1632, 10 nov. 2012. [ISSN n. fornecido]

MINHOTO, L.D. \& MARTINS, C.E. As redes e o desenvolvimento social. Cadernos Fundap, São Paulo, 22:81-101, 2002. ISSN 1807-3131

ORGANIZAÇÃO DAS NAÇÕES UNIDAS (ONU). Assembleia Geral (66, 2011). Political Declaration of the High-level Meeting on the Prevention and Control of Noncommunicable Diseases. Nova Yorque, 19-20 sep. 2011. [on line] Disponível em: http://www.un.org/ga/search/view doc.asp?symbol=A/66/L.1 [ISBN n/fornecido]

ORGANIZAÇÃO DAS NAÇÕES UNIDAS (ONU). Assembleia Geral (67, 2012). Adopting consensus text, General Assembly encourages member states to plan, pursue transition of national health care systems towards universal coverage. (GA/11326) Dec 12, 2012. [on line] Disponível em: http://www.un.org/News/Press/docs/2012/ga11326.doc.htm [ISBN n/fornecido]

ORGANIZAÇÃO PAN-AMERICANA DA SAÚDE (OPAS). Conselho Diretor (52, 2013). Os objetivos de desenvolvimento do milênio e as metas de saúde na Região das Américas. Washington, 30 set.-4 out. 2013. (CD52/INF/4(Port). [on line] Disponível em: https://www.google.com.br/url?sa=t\&rct=j\&q=\&esrc=s\&source=web\&cd=10\&cad=rja\& ved=0CJcBEBYwCQ\&url=http\%3A\%2F\%2Fwww.paho.org\%2Fhq\%2Findex.php\%3Fo ption\%3Dcom docman\%26task\%3Ddoc download\%26gid\%3D22651\%26ltemid\%3D 270\%26lang\%3Dpt\&ei=hLw6UuanO9004AP8rYGYCg\&usg=AFQjCNHLO abVXBip6Q2 R4IOph8D9EvA\&sig2=8SZtfn6l14ytFkUzj2fP g\&bvm=bv.52288139,d.dmg

SILVA, José Afonso. Curso de Direito Constitucional Positivo. (8. ed.)São Paulo: Malheiros, 1992. ISBN 85-7420-686-5 